\title{
Development of Decision Support System for Ordering Goods using Fuzzy Tsukamoto
}

\author{
Andik Setyono, Siti Nur Aeni \\ Department of Informatics Engineering, Dian Nuswantoro University, Semarang, Indonesia
}

\begin{tabular}{l}
\hline \hline Article Info \\
\hline Article history: \\
Received Sep 5, 2017 \\
Revised Jan 3, 2018 \\
Accepted Jan 11, 2018 \\
\hline
\end{tabular}

Keyword:

Decision support system

Defuzzifikasi

Fuzzification

Fuzzy inference system

Tsukamoto method

\begin{abstract}
The determination of a number of items in the right number is very essential for a company, but in actual practice, it is not trivial task. There are many factors that influence them such as inventory and sales levels. If a number of the ordering goods is too slight or too much, it will effect in the fulfillment of consumer demand. One of the ways that can be used to predict a number of ordering goods is a Fuzzy Inference System (FIS) using Tsukamoto fuzzy logic method. Three variables that are used in this study, namely sales, inventory, and ordering or purchasing. The sales input variables are divided into 3 categories, namely down, constant, and rise. Then, inventory input variebles are divided into 3 categories, namely a slight, moderate and many, likewise ordering input variables also consists in 3 categories, namely less, constant, and increase. The next step is the combination of rules from all events, then performing inference and defuzzifikasi to find average centered. To prove the applied method against manual calculations are then implemented in the developed system. The results of the system calculation do not much different with the calculation results that are done by manually. This is proven by information in the table of Mean Squared Error (MSE) with error results of under 1 . So, without prejudice to accuracy in the calculation, the system can be used to save time in determining the amount of the ordering goods. The proposed method can help for research object, in this case is retail company to determine a number of ordering goods.
\end{abstract}

Copyright $@ 2018$ Institute of Advanced Engineering and Science. All rights reserved.

\section{Corresponding Author:}

Andik Setyono,

Departement of Informatic Engineering,

Faculty of Computer Science,

Dian Nuswantoro University,

Jalan Imam Bonjol 207 Semarang, 50131, Indonesia.

Email: andik.setyono@dsn.dinus.ac.id

\section{INTRODUCTION}

A retail company denotes retailer of various goods. In carrying out its business activities, a retail company purchases the products from suppliers and then selling them to their consumers. Buying goods is started by ordering goods. Determining the number of the ordering goods in the right number is very important thing for a company, but the implementation is not easy because there are many factors that affect the amount of inventory and sales levels. If a number of the ordering goods is too slight or too many, it will affect in the fulfillment of consumer demand.

One of the real problems that often appear on the retail company is the difficulty in determining a number of goods that have been purchased in the right number from supplier for the next months. It is caused the sales of goods for every month experiencing fluctuations that is the increases and decreases in demand. Some retail companies usually only rely on estimates in ordering goods for each month. An artificial intelligence is required to be able to overcome these problems. One method of artificial intelligences to perform estimation or prediction is fuzzy logic. With the fuzzy logic, the human intelligent system can be 
implemented into machine language efficiently and easily. Fuzzy logic can be used to draw a conclusion from input data and output data. By using Fuzzy Inference System (FIS), fuzzy logic can map an input to the output [1].

Fuzzy Inference System (FIS) is a theory of reasoning and fuzzy set in the form of IF-THEN based on computational framework. FIS gets crisp input, then sends input through fuzzy rules in the form of IFTHEN. In each rule will be sought fire strength $(\alpha)$. Having more than one rule will aggregate all rules. To get the crisp value as the output, then the result of the aggregation will be defuzzy [1], [2]. In this research, the used FIS method is Tsukamoto. Tsukamoto method can be used to assist in making decisions for determining the amount of ordering goods. This method is consistent with the IF-THEN rules that is depicted in the fuzzy set with the membership function in the form of output. The output results are based on $\alpha$, then the end result is obtained by using defuzzification [3], [4]. The determination of the quantity order of goods with Tsukamoto method is based on inventory and sales data. The data will be represented using the fuzzy membership function.

Manual calculation requires the maximum and minimum of the goods inventory data, maximum and minimum of the goods sales, maximum and minimum ordering goods. The fuzzy calculations will take a long time if it is done manually. To minimize the calculation error and to save time, then Tsukamoto method is applied in Decision Support System (DSS). Applying the fuzzy method to the decision support system is expected to assist in making goods ordering decisions. The data in the input variables will then be processed by the decision support system by using the Tsukamoto method and display the output of the number of goods to be made reservations [5], [6].

Based on the previous research, the authors choose the method of Tsukamoto in the case of ordering goods for retail companies because this method uses the average weight-output (weight average) is very simple and easy to understand. This study is still relevant to the current conditions, where the application of artificial intelligence can help people in making decisions in this case for determining the number of ordering goods in the next month quickly.

\section{RESEARCH METHOD AND LITERATURE REVIEW}

\subsection{Reasearch Method}

In this study, the first step that is done by authors is observation and then followed by literature review. Observation is done to get information, understanding, and knowledge about the problems that are faced by a retail company as the reserach object. Then, the next step is lieterature review to analize and find solution for the problems and using theory that become basis of the information and some related ideas that come from books, journals, proceedings, and papers.

In this study, authors used the secondary data that are obtained through a series of data collection methods and data query of the related research. This data are obtained from the collection of documents which have been recorded periodically. The data contains the number of sales, the amount of inventory and the number of orders for each month. The data will be used as input to the system. The data represents relating data to the conditions of the two input variables and one output variable. The following variables will be used in this study: a) Sales input variables are divided into 3 categories namely down, constant and rise. b) Inventory input variables are divided into 3 categories: slight, moderate, many. c) Order output variables are divided into 3 categories namely less, constant, and increased.

This research begins with collecting data that contained in a retail company, then the obtained data required that are ordering goods data starting in 2015 until 2016. After the data obtained or collected then the data are processed using the Tsukamoto method. The obtained results then are performed a comparison by using manual calculations. There are several steps that are done from the obtained data, the first fuzzification in the form of fuzzy set and membership function. Then proceed with rules in the form of IF-THEN to connect various information with other information so that it can be concluded. Furthermore, Fuzzy Inference System (FIS) aims to send input through fuzzy rules in the form of IF-THEN. Further, defuzzification is used to change the output that has been obtained through the FIS stage becomes a firm value by using the membership function contained in the filling [7].

Testing is conducted to determine the success rate in the implementation of Inferenced Fuzzy Tsukamoto system for ordering goods. Testing is performed by way of comparison of ordering goods using the system with reservations contained in a retail company. Testing the accuracy level in this system using the Mean Squared Error (MSE) method, and here is the formula [7]:

$$
M S E=\frac{\sum e^{2}}{n}
$$


The accuracy of data testing can be seen based on the MSE obtained from each method. MSE is a method for analyzing or measuring data errors. This MSE method is used to determine the best defuzzification methods. Figure 1 is the flow of research activities below:

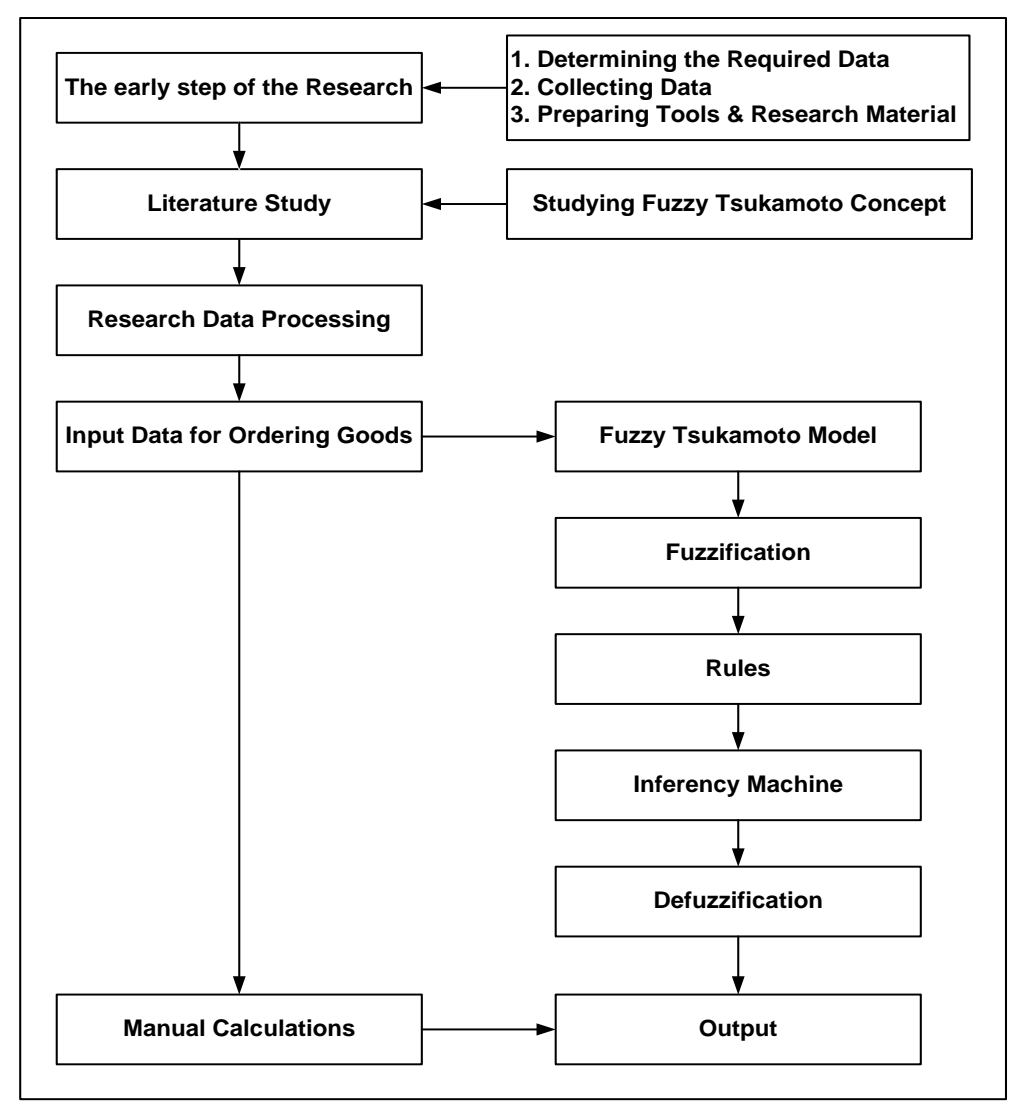

Figure 1. Flow of research activities

\subsection{Literature Review}

\subsubsection{Logika Fuzzy}

In 1962 Prof. Lotfi Astor Zadeh introduces fuzzy logic. To solve the problem of control system required methodology by using fuzzy logic. The solution of this problem is appropriate to apply to control systems, computer network, workstations, simple systems and small systems. The methodology used can be implemented with hardware, software or combination of them. All that is in classical logic has a binary nature that has two possibilities, "True or False", "Yes or No", and so on. So the value of membership 1 or 0 can have everything. However, membership value 1 or 0 only consists of two values: "True and False", "Yes and No" simultaneously, but belonging to the weight of the membership process depends on the magnitude of the value [8], [9]. Fuzzy logic is one that can describe the input to output space and has an ongoing value. Fuzzy logic is expressed by degrees of authenticity and membership. Therefore everything is either wrong or true at the same time [2].

The fuzzy set is also called crisp, set B has a membership value y so it can be written like this [x], which has 2 possible values as follows [10]: (a) One means a set has a membership value of a particular item. (b) Zero means a set has no membership value of a particular item. The reason for using fuzzy logic is as follows: (a) it is easy to understand, because the mathematical set theory as the basis of fuzzy is easy to understand, (b) flexible to modification and uncertainty issues, (c) has acceptance on the data that is less precise, and d) Using language that is easy to understand. The two attributes that is possessed by the fuzzy set are as follows [10]: (a) Linguistics: naming the set using everyday language to replace under certain conditions, For example SLOW, MEDIUM, QUICK replace variable speed. (b) Numerical: a number that shows the parameters of a variable, for example 15, 30, 45 and others.

Figure 2 show the fuzzy set. 


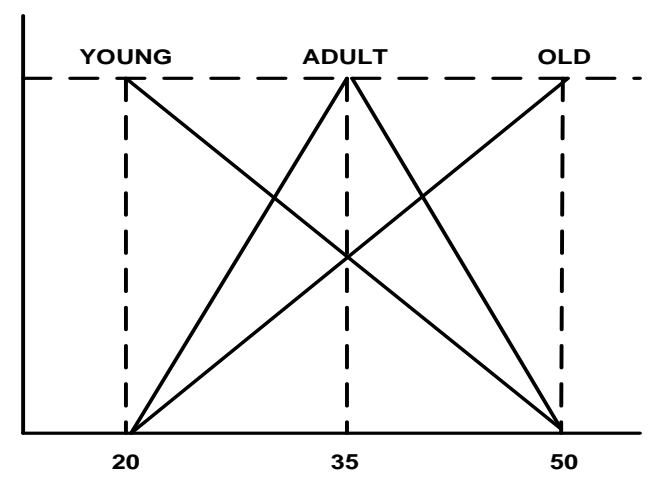

Figure 2. Fuzzy set

The universe of conversation is all the numbers that have been approved to perform operations within the fuzzy variables. The fuzzy set domain is all the approved numbers that exist within the speech universe and can operate to the fuzzy set. The membership degree for each input variable lies between intervals 0 and 1 is a membership function. The variable $\mathrm{x}$ that exists within the membership level is denoted by $\mu(\mathrm{x})$. To get conclusion every rule must use the value of membership as a factor consideration in determining the effect of time inference.

The reasoning and fuzzy set in the form of IF-THEN is based on a computational framework called the Fuzzy Inference System (FIS). FIS obtains crisp input, then sends input through fuzzy rules in the form of IF-THEN. Having more than one rule will aggregate all rules. Then to get the crisp value as output, the result of the aggregation will be defuzzy [3]. There are 3 stages that can be applied to fuzzy logic [3]: (a) Fuzzification or blurring: mapping input into the fuzzification set, (b) Fuzzy Inference System: generating fuzzification rules, and (c) Defuzzification: transforming output from fuzzification to a firm value. Rule is a knowledge structure that connects to various information with other information so that it can be concluded. The Rule contained in the IF will connect one or more premises and at THEN will connect one or more conclusions. Rule can have more than one premise by linking the conjunction (AND) statement and the disjunction statement (OR) or a combination of the two [3], [6], [7].

Tsukamoto's method applies monotonous reasoning to every rule. In monotonous reasoning, the system has only one rule. In Tsukamoto's method, the system consists of several rules. Because using the basic concept of monotonous reasoning, in Tsukamoto's method, any consequence on the IF-THEN rules must be represented by a fuzzy set with a monotonous membership function. Output of inference results of each rule is given explicitly (crisp) based on $\alpha$-predicate (fire strength). Aggregation process between rules is done, and the end result is obtained by using defuzzy with the weighted average concept [3]. Suppose there are input variables, namely $\mathrm{x}$ and $\mathrm{y}$, and one output variable that is $\mathrm{z}$. Variable $\mathrm{x}$ is divided into 2 sets that is $\mathrm{A} 1$ and $\mathrm{A} 2$, variable $\mathrm{y}$ is divided over 2 set also, that is $\mathrm{B} 1$ and $\mathrm{B} 2$, whereas variable of output $\mathrm{Z}$ is divided into 2 set that is $\mathrm{C} 1$ and $\mathrm{C} 2$. Of course the set $\mathrm{C} 1$ and $\mathrm{C} 2$ must be a monotonous set. Given 2 rules as follows:

$$
\begin{aligned}
& \text { IF } x \text { is } A 1 \text { and } y \text { is } B 2 \text { THEN } z \text { is } C 1 \\
& \text { IF } x \text { is } A 2 \text { and } y \text { is } B 1 \text { THEN } z \text { is } C 2
\end{aligned}
$$

$\alpha$-predicate for the first and second rule, respectively are A1 and A2. Using monotonic reasoning, obtained the value of $\mathrm{Z} 1$ in the first rule, and $\mathrm{Z} 2$ in the second rule. Lastly by using weighted rule

\subsubsection{Decision Support System}

The development of a decision support system (DSS) began around 1960, but a new decision support system was introduced in 1971, that is introduced by Michael S. Scott Morton and G. Antony Gorry for management decision-making purposes to create a framework using computer applications. Decisionmaking using specific data and models in computer-based systems can help solve a variety of unstructured problems. Computers can be utilized by the DSS in the decision-making process. DSS is a computer-based information system that is used to make decisions on a company or organization. In another definition, it is said that computer-based systems support in processing data into information for decision-making from the problem of explicit semi-structured [11].

In principle, in making a decision is based on a problem in an effort to obtain a certain goal. The goal is to be able to overcome or solve interrelated problems so that in carrying out its objectives that can be done effectively and efficiently. Decision-making is to define a series of activities to achieve the expected 
results. Decision-making becomes one way in solving problems that have a function as the root of all human activities that are targeted individually or in groups as well institutions and organizations. In addition, decision making has a futuristic function, which means concerned with the future time, which has a longstanding effect. There are several stages in the decision-making process as follows [11]:

a. Intelligence

At this stage, the inputted data is obtained, data is processed, and test data to identify the problem.

b. Design

At this stage can be analyzed to solve the problem that is by designing a model that can replace the problem in real conditions. This stage is obtained by output in the form of problem solving option.

c. Choice

At this stage, the action can be done from a variety of alternatives that may be run through the selection process so it can be obtained solution documents and implementation plans.

d. Implementation

At the stage of choice, solutions that have been applied to obtain the results. Figure 3 describes flow of the process of taking a decision.

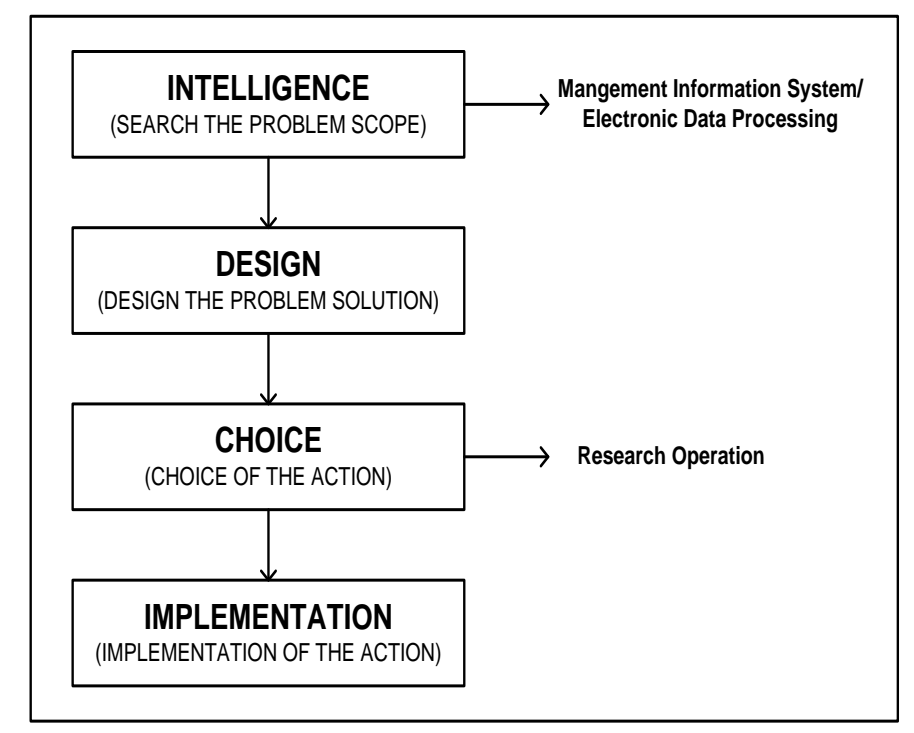

Fugure 3. The process of taking a decision

Some characteristics in decision support systems are: (a) providing support in decision making, especially to unstructured and semi-structured situations, (b) providing support for independent decision making, (c) improving the effectiveness of decision making rather than efficiency, (d) providing support for various decision-making process and e) provide support to individuals and groups. The purpose of decision support systems are: (a) to support the role of managers to make decisions in solving problems either structured or unstructured, (b) provide support for managers' decisions rather than aimed at changing the manager's role. Computers can only solve structured problems while managers can solve unstructured problems. The role of manager and computer can be combined into one to solve problems, (c) improve the effectiveness of manager decisions [12].

\section{RESULTS AND ANALYSIS}

\subsection{Fuzzy Tsukamoto Calculations}

Some things have to be considered when perform calculating the optimization of ordering goods using fuzzy with Tsukamoto method, namely by arranging membership/ fuzzification function, determine the rules/ fuzzy rules, inference and determine the output crisp. 


\subsubsection{Fuzzification}

In this study, the membership function for each fuzzy variable uses a triangle, linear down and linear rise as an approach to get the value of a degree of membership in the fuzzy set.

a. Sales Input Variables

Sales input variables are divided into 3 categories: DOWN, CONSTANT, RISE. The fuzzy set of DOWN membership function is linear down, fuzzy set CONSTANT membership function is triangle and fuzzy set RISE membership function is linear rise. Membership function in each set is formulated in Equations (2), (3) and (4).

$$
\begin{aligned}
& \mu_{\text {DoWN }}[x]=\left\{\begin{array}{cc}
1 & x \leq 600 \\
900-x & 600 \leq x \leq 980 \\
\cline { 1 - 1 } 380 & x \geq 980
\end{array}\right.
\end{aligned}
$$

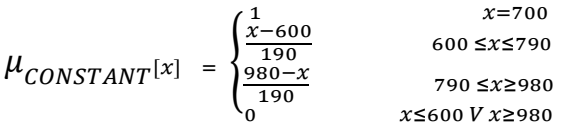

$$
\begin{aligned}
& \mu_{R I S E}[x]=\left\{\begin{array}{cc}
0 & x \leq 600 \\
x-600 & 600 \leq x \leq 980 \\
\hdashline 380 & x \geq 980
\end{array}\right.
\end{aligned}
$$

Membership values in fuzzy set DOWN, CONSTANT and RISE for sales input variables of 610 pieces are as follows:

$\mu \mathrm{DOWN}[610]=(980-610) / 380=0,97368$

$\mu$ CONSTANT $[610]=(610-600) / 190=0,05263$

$\mu \mathrm{RISE}[610]=(610-600) / 380=0,02632$

b. Inventory Input Variables

Inventory input variables are divided into 3 categories: SLIGHT, MODERATE, MANY. The fuzzy set of SLIGHT membership functions is linear down, the fuzzy set of MODERATE membership function is triangular and the fuzzy set of MANY of membership functions is linear rise. Membership function in each set is formulated in Equations (5), (6) and (7).

$$
\begin{gathered}
\mu_{\text {SLIGHT }}[y]=\left\{\begin{array}{cc}
1 & y \leq 185 \\
\frac{372-y}{187} & 85 \leq y \leq 372 \\
0 & y \geq 372
\end{array}\right. \\
\mu_{\text {MODERATE }}[y]=\left\{\begin{array}{cc}
1 & y=278.5 \\
\frac{y-185}{93.5} & 185 \leq y \leq 278.5 \\
\frac{372-y}{93.5} & 278.5 \leq y \geq 372 \\
0 & y \leq 185 V y \geq 372
\end{array}\right. \\
\mu_{M A N Y}[y]=\left\{\begin{array}{cc}
0 & y \leq 185 \\
y-185 & 185 \leq y \leq 372 \\
\frac{187}{1} & y \geq 372
\end{array}\right.
\end{gathered}
$$

The membership value in fuzzy set SLIGHT, MODERATE and MANY for the 210 peaces inventory input variables are as follows:

$\mu \operatorname{LESS}[210]=(372-210) / 187=0,86631$

MMODERATE $[210]=(210-185) / 93,5=0,26738$

$\mu$ MANY $[210]=(210-185) / 187=0,13369$

c. Purchasing Input Variables

Purchasing Input Variables are divided into 3 categories: LESS, CONSTANT, INCREASED. The LESS fuzzy set membership function is linear down, CONSTANT fuzzy set membership function is triangle and INCREASED fuzzy set membership function is linear rise. Membership function in 
each set is formulated in Equations (8), (9) and (10).

$$
\begin{aligned}
& \left\{\begin{array}{cc}
1 & Z \leq 580 \\
765-Z & 580 \leq 8 \leq 765
\end{array}\right. \\
& \mu_{\text {LESS }^{[Z]}}=\left\{\begin{array}{cc}
{ }^{765-Z} & 580 \leq Z \leq 765 \\
\hline 185 & Z \geq 765 \\
0 &
\end{array}\right.
\end{aligned}
$$

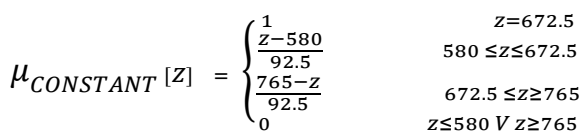

$$
\begin{aligned}
& \mu_{I N C R E A S E D^{[Z]}}=\left\{\begin{array}{cc}
0 & z \leq 580 \\
z-580 & 580 \leq z \leq 765 \\
\hline 185 & z \geq 765 \\
1 &
\end{array}\right.
\end{aligned}
$$

\subsubsection{Inferences}

Then combining the rules of all events. It is done to obtain a fuzzy output value of a fuzzy input value. The mechanism is a fuzzy input value that starts from fuzzification then put into the rules that have been made fuzzy output. The rules that are used in performing fuzzy calculations are as follows:

[R1] IF Sales is DOWN and Inventory is MANY THEN ordering is LESS;

[R1] in the fuzzy rule is denoted as P1 whose formula can be obtained from:

$$
\begin{aligned}
\text { P1 } & =\mu \text { Sal_Down, Invent_Many } \\
& =\min (\mu \text { Sal_Down [610], Invent_Many [210] }) \\
& =\min (0,97368,0,13369) \\
& =0,13369
\end{aligned}
$$

Based on the membership function for the goods ordering set LESS in accordance with [R1] contained in fuzzy rules then $\mathrm{Z} 1$ can be obtained by:

$$
\begin{aligned}
& Z 1=765-0,13369(765-580) \\
& Z 1=(765-24,73265) \\
& Z 1=740,26735
\end{aligned}
$$

[R2] IF Sales is DOWN and Inventory is MODERATE THEN ordering is LESS;

$[R 2]$ in the fuzzy rule is denoted as P2 whose formula can be obtained from:

$$
\begin{aligned}
\text { P2 } & =\mu \text { Sal_Down, Invent_Medium } \\
& =\min (\mu \text { Sal_Down [610], Invent_Medium [210] }) \\
& =\min (0,97368,0,26738) \\
& =0,26738
\end{aligned}
$$

Based on the membership function for the goods ordering set LESS in accordance with [R2] contained in fuzzy rules then $\mathrm{Z} 2$ can be obtained by:

$$
\begin{aligned}
& Z 2=765-0,26738(765-580) \\
& Z 2=(765-49,4653) \\
& Z 2=715,5347
\end{aligned}
$$

[R3] IF Sales is DOWN and Inventory is LESS THEN Ordering is LESS;

$[\mathrm{R} 3]$ in the fuzzy rule is denoted as P3 whose formula can be obtained from:

$$
\begin{aligned}
\text { P3 } & =\mu \text { Sal_Down, Invent_Less } \\
& =\min (\mu \text { Sal_Down [610], Invent_Less [210]) } \\
& =\min (0,97368,0,86631) \\
& =0,86631
\end{aligned}
$$

Based on the membership function for the goods ordering set LESS in accordance with [R3] contained in fuzzy rules then $\mathrm{Z} 3$ can be obtained by: 


$$
\begin{aligned}
& Z 3=765-0,86631(765-580) \\
& Z 3=(765-160,26735) \\
& Z 3=604,73265
\end{aligned}
$$

[R4] IF Sales is CONSTANT and Inventory is MANY THEN Ordering is LESS;

$[\mathrm{R} 4]$ in the fuzzy rule is denoted as P4 whose formula can be obtained from:

$$
\begin{aligned}
\text { P4 } & =\mu \text { Sal_Fixed, Invent_Many } \\
& =\min (\mu \text { Sal_Fixed [610], Invent_Many [210] }) \\
& =\min (0,05263,0,13369) \\
& =0,05263
\end{aligned}
$$

Based on the membership function for the goods ordering set LESS in accordance with [R4] contained in fuzzy rules then $\mathrm{Z} 4$ can be obtained by:

$$
\begin{aligned}
& Z 4=765-0,05263(765-580) \\
& Z 4=(765-9,73655) \\
& Z 4=755,26345
\end{aligned}
$$

[R5] IF Sales is CONSTANT and Inventory is MODERATE THEN ordering is CONSTANT;

[R5] in the fuzzy rule is denoted as P5 whose formula can be obtained from:

$$
\begin{aligned}
\text { P5 } & =\mu \text { Sal_Fixed, Invent_Medium } \\
& =\min (\mu \text { PnjTetap[610],Invent_Medium [210] }) \\
& =\min (0,05263,0,26738) \\
& =0,05263
\end{aligned}
$$

Because the goods ordering is CONTANT, It will be seen directly that Z5 $=\mathrm{z}=672.5$.

[R6] IF Sales is CONSTANT and Inventory is SLIGHT THEN Ordering is INCREASED;

[R6] in the fuzzy rule is denoted as P6 whose formula can be obtained from:

$$
\begin{aligned}
\text { P6 } & =\mu \text { Sal_Fixed,Invent_Less } \\
& =\min (\mu \text { Sal_Fixed [610], Invent_Less [210]) } \\
& =\min (0,05263,0,86631) \\
& =0,05263
\end{aligned}
$$

Based on the membership function for the goods ordering set INCREASED in accordance with [R6] contained in fuzzy rules then Z6 can be obtained by:

$$
\begin{aligned}
& Z 6=0,05263(765-580)+580 \\
& Z 6=(9,73655+580) \\
& Z 6=589,73655
\end{aligned}
$$

[R7] IF Sales is RISE and Inventory is MANY THEN ordering is INCREASED;

[R7] in the fuzzy rule is denoted as P7 whose formula can be obtained from:

$$
\begin{aligned}
\text { P7 } & =\mu \text { Sal_Up, Invent_Many } \\
& =\min (\mu \text { Sal_Up }[610], \text { Invent_Many }[210]) \\
& =\min (0,02632,0,13369) \\
& =0,02632
\end{aligned}
$$

Based on the membership function for the goods ordering set INCREASED in accordance with [R7] contained in fuzzy rules then $\mathrm{Z7}$ can be obtained by:

$$
\begin{aligned}
& \mathrm{Z} 7=0,02632(765-580)+580 \\
& \mathrm{Z} 7=(4,8692+580) \\
& \mathrm{Z} 7=584,8692
\end{aligned}
$$


[R8] IF Sales is RISE and Inventory is MODERATE THEN Ordering is INCREASED;

[R8] in the fuzzy rule is denoted as P8 whose formula can be obtained from:

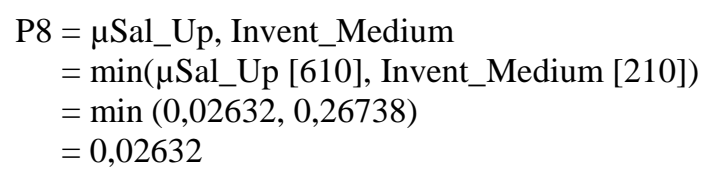

Based on the membership function for the goods ordering set INCREASED in accordance with [R8] contained in fuzzy rules then Z8 can be obtained by:

$$
\begin{aligned}
& Z 8=0,02632(765-580)+580 \\
& Z 8=(4,8692+580) \\
& Z 8=584,8692
\end{aligned}
$$

[R9] IF Sales is RISE and Inventory is SLIGHT THEN Ordering is INCREASED;

[R9] in the fuzzy rule is denoted as P9 whose formula can be obtained from:

$$
\begin{aligned}
\text { P9 } & =\mu \text { Sal_Up, Invent_Less } \\
& =\min (\mu \text { Sal_Up }[610], \text { Invent_Less }[210]) \\
& =\min (0,02632,0,86631) \\
& =0,02632
\end{aligned}
$$

Based on the membership function for the goods ordering set INCREASED in accordance with [R9] contained in fuzzy rules then Z9 can be obtained by:

$$
\begin{aligned}
& Z 9=0,02632(765-580)+580 \\
& Z 9=(4,8692+580) \\
& Z 9=584,8692
\end{aligned}
$$

\subsubsection{Defuzzification}

To get the output value (crisp) is to convert the input into a number on the fuzzy set domain or defuzification. Having obtained the value of $\mathrm{Pi}$, then the next will be done the calculation process of the value for each consequent rules $(\mathrm{Zi})$ in accordance with the membership function used. The method of defuzification in the Tsukamoto method is the Center Average Defuzzyfier that is deflected by:

$$
\begin{aligned}
Z & =\frac{P 1 * Z 1+P 2 * Z 2+P 3 * Z 3+P 4 * Z 4+P 5 * Z 5+P 6 * Z 6+P 7 * Z 7+P 8 * Z 8+P 9 * Z 9}{P 1+P 2+P 3+P 4+P 5+P 6+P 7+P 8+P 9} \\
& =\frac{966,534249161}{1,50423} \\
& =642,54
\end{aligned}
$$

So the number of ordering goods for next month is 643 with sales of 610 and 210 inventory.

\subsection{Implementation of Decision Support System with Tsukamoto Method}

In the implementation of this decision support system, Tsukamoto method is applied by using a programming language to determine the amount of the goods ordering based on sales and inventory data. Tsukamoto method can be applied well in the application of decision support system to determine the amount of ordering next month. The following is a view of the developed system application as shown in Figure 4 and Figure 5. 


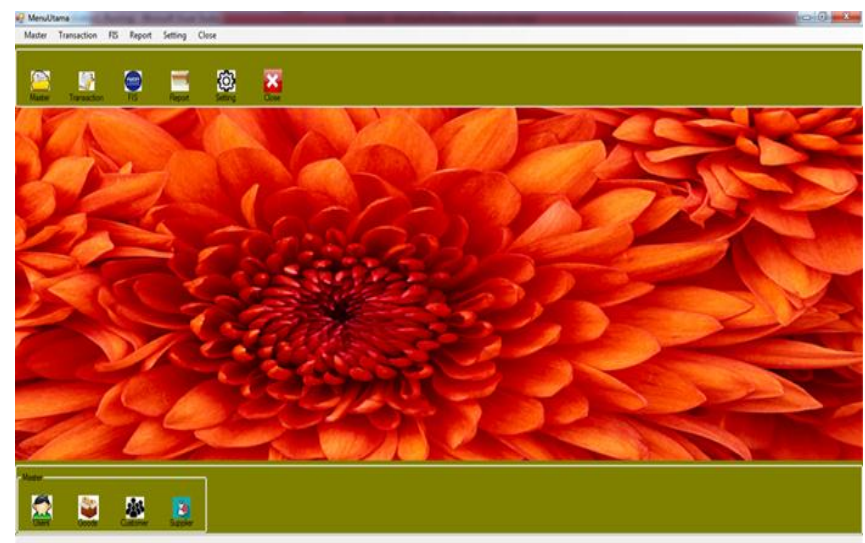

Figure 4. Menu of the developed system application

In the developed system, there are several menus where the main discussion in this paper is Fuzzy Inference System (FIS) menu to determine the number of subsequent ordering goods using Tsukamoto method. Figure 5 illustrates the user interface of applying the Fuzzy Tsukamoto algorithm to the developed system application.

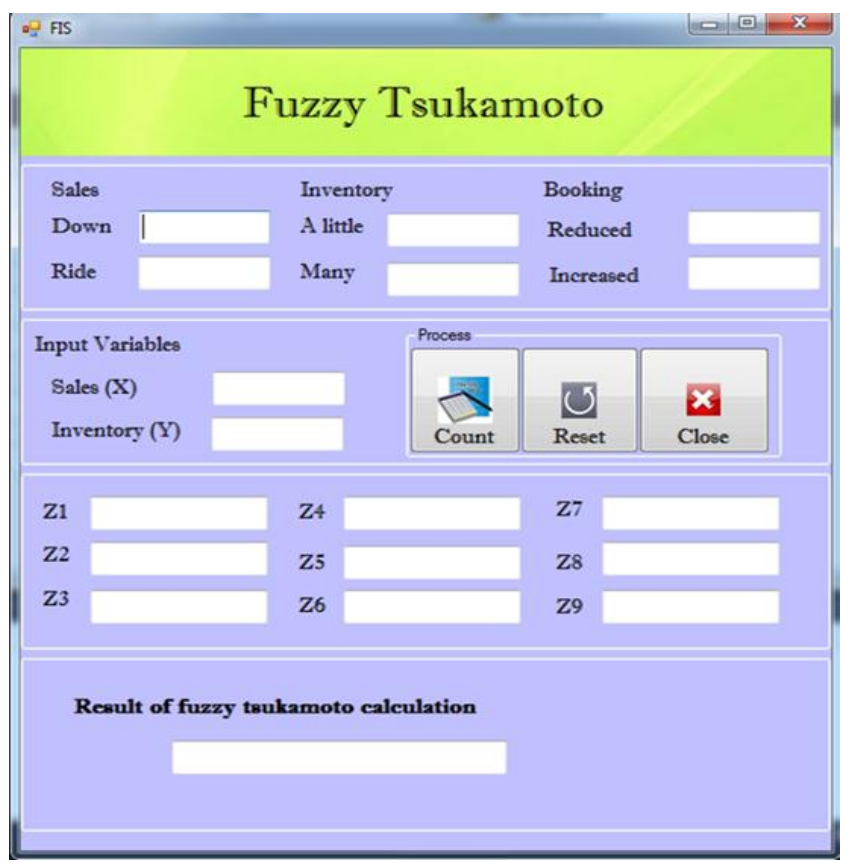

Figure 5. User interface of the fuzzy tsukamoto calculation

\subsection{Testing Mean Square Error (MSE)}

The accuracy of data testing can be seen based on the MSE that is obtained from each method. MSE is a method for analyzing or measuring data errors. The MSE method is used to determine the best defuzzification methods. The following is the comparison result using the Tsukamoto method calculation with the ordering goods data that found in research object which will be presented in Table 1 .

Based on the comparison above can be concluded that the manual prediction on the company compared to the calculation using the method has an error of 0.20815 . So it can be concluded that the methods on this system can work well and can be applied in research object. 
Table 1. Comparing result beetween the existing and the proposed methods

\begin{tabular}{|c|c|c|c|c|}
\hline Month & Ordering & Ordering DSS & Difference & Squared Difference \\
\hline Nov - 15 & 600 & 644 & 0,44 & 0,1936 \\
\hline Des -15 & 620 & 666 & 0,46 & 0,2116 \\
\hline Jan -16 & 725 & 679 & $-0,46$ & 0,2116 \\
\hline $\mathrm{Feb}-16$ & 630 & 686 & 0,56 & 0,3136 \\
\hline Mar -16 & 585 & 623 & 0,38 & 0,1444 \\
\hline Apr -16 & 620 & 688 & 0,68 & 0,4624 \\
\hline Mei - 16 & 650 & 687 & 0,37 & 0,1369 \\
\hline \multicolumn{4}{|c|}{ Number of Squared Difference } & 2,0815 \\
\hline \multicolumn{4}{|c|}{$\mathrm{MSE}=$ Number of Squared Difference } & 0,20815 \\
\hline
\end{tabular}

\section{CONCLUSION AND FUTURE WORK}

Based on the reviews that have been presented about the implementation of Fuzzy Tsukamoto in Decision Supporting System of Ordering Goods then can be drawn the conclusion. In applying the Fuzzy Inference System (FIS) by using the Tsukamoto method to determine the number of goods ordering, there are 3 steps that are performed, namely fuzzification, inference and defuzification. The developed system has been made to predict the number of ordering goods in a retail company, so it can be run efficiently. In future work, the fuzzy variables that are used for input should be more than 3 variables, it will generate the better results when the variables are more complex.

\section{REFERENCES}

[1] Patil P and Patel, "A Comprehensive Review On Fuzzy Logic System," International Journal of Engineering And Computer Science. 2014; 3(11); 9160-9165.

[2] Bojadziev G and Bojadziev M, 'Fuzzy Logic for Business, Finance, and Management," World Scientific Publishing, Singapore, 2007.

[3] Timothy J, "Fuzzy Logic with Engineering Application, Second Edition”, John Wiley \& Sons. Ltd. England, 2004.

[4] Kumaran K and Kailas A, "Prediction of Future Stock Close Price using Proposed Hybrid ANN Model of Functional Link Fuzzy Logic Neural Network," IAES International Journal of Artificial Intelligent (IJ-AI), 2012;1(1);25-30.

[5] Andino M and Mahmud H, "Finding Kicking Range of Sepak Takraw Game: A Fuzzy Logic Approach," TELKOMNIKA (Telecommunication Computing Electronics and Control), 2015; 14(3); 557-564.

[6] Rohaizan BR and Ang PC, "The Conceptual Framework of Production Planning Optimisation using Fuzzy Inference System With Tsukamoto," International Journal of Industrial Management (IJIM), 2016; Volume 2; 80-91.

[7] Mochammad IP, Andre HL, Imelda SD, Raheliya BG, and Andyshah PUS, "Implementation of Fuzzy Tsukamoto Algorithm in Determining Work Feasibility," IOSR Journal of Computer Engineering (IOSR-JCE), 2017; 19(4); $52-55$.

[8] Ikhsan KF, "Penerapan Fuzzy Tsukamoto Dalam Sistem Pendukung Keputusan Untuk Menentukan Jumlah Produksi Barang (Implementation of Tsukamoto Fuzzy in Decision Support System to Determine the Number of Goods Production," Proseding Seminar Bisnis \& Teknologi, 2014.

[9] Sutojo T, Mulyanto E, and Suhartono V, “Kecerdasan Buatan (Artificial Intelligence)," Yogyakarta: Andi Offset, 2010.

[10] Mutammimul U, "Implementasi Logika Fuzzy Dalam Optimasi Jumlah Pengadaan Barang Menggunakan Metode Tsukamoto (Studi Kasus : Toko Kain)/Implementation of Fuzzy Logic In Optimizing Number of Goods Procurement Using Tsukamoto Method: Case Study: My Text Textile Store," Jurnal Ecotipe, Universitas Malikussaleh. 2014; 1(11).

[11] Fakhry H, "A Fuzzy Logic Based Decision support System for Business Situation Assessment and e-Business Models Selection," Communications of the IIMA, 2010; 10(4).

[12] Abdurrahman G, "Penerapan Metode Tsukamoto (Logika Fuzzy) Dalam Sistem Pendukung Keputusan Untuk Menentukan Jumlah Produksi Barang Berdasarkan Data Persediaan Dan Jumlah Permintaan (Impementation of the Tsukamoto Method (Fuzzy Logic) In Decision Support System to Determine the Number of Goods Production Based on Inventory Data and Number of Demand), Thesis Report, Universitas Negeri Yogyakarta, 2011. 


\section{BIOGRAPHIES OF AUTHORS}

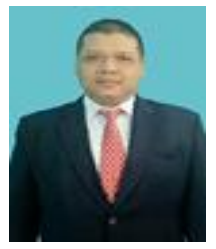

Andik Setyono is a lecturer in Department of Informatic Engineering, Faculty of Computer Science, Dian Nuswantoro University, Semarang-Indonesia. He graduated from Multimedia University (MMU) Malaysia for his Ph.D in Information Technology. His research areas are wireless and mobile computing, network management, image processing and database.

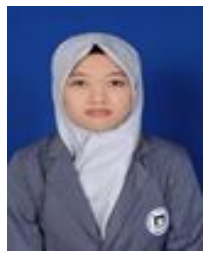

Siti Nur Aeni is a student in Department of Informatics Engineering, Faculty of Computer Science, Dian Nuswantoro University, Semarang-Indonesia. She has just graduated for her degree. 